\title{
Programa Articuladores da Atenção Básica: construindo humanização através do diálogo
}

\section{I ${ }^{1}$ Giovanna Cabral Doricci, 2 Carla Guanaes-Lorenzi, ${ }^{3}$ Maria José Bistafa Pereira I}

Resumo: A Política Nacional de Humanização (PNH) preconiza o aprimoramento da prestação dos serviços de saúde através da valorização dos sujeitos implicados nesse processo e suas formas de interação. A Psicologia tem sido um importante referencial de reflexões e análises sobre a humanização no campo da Saúde Pública. O objetivo deste artigo é analisar uma das atividades técnicas dos articuladores da Atenção Básica, profissionais de um novo programa de São Paulo, a partir dos preceitos estabelecidos pela $\mathrm{PNH}$ e de sua interface com os estudos da Psicologia Social. Para isso, foram entrevistados individualmente 13 articuladores da Atenção Básica. A análise é qualitativa, com respaldo teórico nas contribuições do movimento construcionista social. Como resultados, são apresentadas três implicações da atuação dos articuladores e que possibilitam a promoção da humanização: ampliação da comunicação intra e intergrupos; escuta das necessidades locais e promoção de espaços para discussão.

> Palavras-chave: Atenção Básica; administração de saúde; humanização do cuidado; comunicação.

\author{
1 Universidade de São Paulo, \\ Faculdade de Filosofia, \\ Ciências e Letras de Ribeirão \\ Preto. Ribeirão Preto-SP, Brasil \\ (dorigica@gmail.com). \\ 2 Universidade de São Paulo, \\ Faculdade de Filosofia, \\ Ciências e Letras de Ribeirão \\ Preto. Ribeirão Preto-SP, Brasil \\ (carlaguanaes@ffclrp.usp.br). \\ ${ }^{3}$ Universidade de São Paulo, \\ Faculdade de Enfermagem \\ Preto. Ribeirão Preto-SP, Brasil \\ (zezebis@eerp.usp.br).
}


A Reforma Sanitária do Brasil encontra-se em pleno processo desde o Movimento da Reforma Sanitária, o qual proporcionou a criação do Sistema Único de Saúde (SUS). Desde então, os esforços na área da saúde coletiva têm sido em busca da criação e fortalecimento de ações práticas que auxiliem na gradativa transformação do modelo assistencial em saúde, ações que contribuam para a construção de um sistema de saúde que seja universal, equânime e integral, voltado às necessidades específicas de cada região.

Esse movimento na área da saúde tem fomentado a construção de políticas públicas, como, por exemplo, a Política Nacional de Atenção Básica (PNAB) e a Política Nacional de Humanização (PNH), entre outras, e de programas específicos, como o Programa Nacional de Melhoria do Acesso e da Qualidade da Atenção Básica (PMAQ) e o Programa de Requalificação das Unidades Básicas de Saúde, voltados para incrementar ou operacionalizar os princípios e diretrizes que compõem a organização do SUS. Os conhecimentos oriundos de diferentes disciplinas têm participado desse processo de construção das políticas públicas e pautado uma concepção mais complexa e ampla da saúde, reconhecendo a diversidade de dimensões que podem ser consideradas para a prática.

A Psicologia Social corresponde a uma das disciplinas dedicadas aos estudos neste campo, que através de pesquisas e inserções na prática cotidiana dos serviços de saúde tem contribuído oferecendo importantes subsídios, teóricos e práticos, para a análise e construção de políticas de saúde (TIVERON; GUANAESLORENZI, 2013; SILVA; RASERA, 2014; PINHEIRO; GUANAESLORENZI, 2014; CAMARGO-BORGES, 2007; CADONÁ; SCARPARO, 2015; MOREIRA et al., 2015). De maneira geral, a Psicologia Social constrói conhecimentos a respeito do modo como os sujeitos em interação, ou as sociedades em nível macro ou microssocial, organizam-se (IBÁÑEZ GRACIA, 1993). Sendo assim, esta disciplina pode contribuir também para analisarmos políticas públicas, uma vez que compreendemos que elas se concretizam no cotidiano das práticas (FRANCO; MERHY, 2006) e que transformaçôes culturais, como a própria Reforma Sanitária, dependem das interações estabelecidas nos microcontextos.

Entre os programas criados para os fins descritos, o Programa de Apoio Técnico à Atenção Básica do Sistema Único de Saúde no Estado de São Paulo nomeado, por Andrade e Castanheira (2011), como Programa Articuladores da Atenção 
Básica corresponde a uma iniciativa da Secretaria Estadual da Saúde de São Paulo

(SES-SP) para oferecer suporte técnico à gestão municipal na qualificação da Atenção Básica (AB). Implantado em 2009 e ainda pouco divulgado no âmbito da literatura científica, este programa inclui na área da saúde uma nova função profissional, a do articulador da atenção básica.

Embora grande destaque seja dado ao aspecto técnico desta função, é possível reconhecer, a partir da fala dos articuladores, ações, e possíveis implicações destas, que favorecem a humanização no contexto do SUS. Ainda que este não seja o foco do articulador da atenção básica (a Secretaria Estadual de Saúde criou para este enfoque o articulador da humanização, conforme resolução SS-7, de 20/01/2012), considera-se relevante reconhecer também este potencial que se desenvolve em alguns contextos práticos de sua atuação.

$\mathrm{O}$ presente artigo discute a prática do articulador e seu potencial para fortalecer a humanização ao promover e intermediar diálogos que conformam, operacionalmente, a comunicação, preceito destacado na literatura que discute a PNH. A análise proposta fundamenta-se nas contribuições do movimento construcionista social em Psicologia Social. Para tanto, organizamos este artigo em dois momentos. Em um primeiro momento, apresentamos brevemente o Programa dos Articuladores da Atenção Básica e também a PNH, mostrando aproximações possíveis entre estes dois campos. Na sequência, e fundamentadas por esta teorização inicial, as informações sobre uma pesquisa realizada com articuladores da atenção básica, na qual analisamos, especificamente, como a atividade técnica "visitas aos municípios" (DORICCI, 2014) se mostra como um recurso potencialmente útil para promoção da humanização na $\mathrm{AB}$.

\section{O Programa Articuladores da Atenção Básica}

O Programa dos articuladores da atenção básica se constitui como uma proposta recente da Secretaria Estadual da Saúde de São Paulo. Lançado em 2009, o programa visa concretizar o papel previsto de assessoria técnica da Secretaria Estadual de Saúde aos municípios, e à nova configuração de gestão compartilhada. Este programa surge como uma resposta à reaproximação do estado (ANDRADE; CASTANHEIRA, 2011), que esteve afastado da gestão ao longo dos anos 1990 devido ao processo de municipalização (ANDRADE; CASTANHEIRA, 2011; MENDES, 2001). Assim, com a criação de uma nova função profissional, a do 
articulador da atenção básica, a SES-SP ampliou a gestão estadual, oferecendo suporte técnico à gestão municipal na promoção e qualificação da $\mathrm{AB}$ no estado. Este programa atende prioritariamente aos municípios com menos de $100 \mathrm{mil}$ habitantes, sendo um articulador por Região de Saúde.

Por ser um programa novo, seu formato tem se configurado no cotidiano de trabalho, por meio das práticas desses novos profissionais. Embora a resolução SS-61, de 14/06/2011 (SÃO PAULO, 2011), verse sobre este programa, são poucas as informações encontradas na literatura científica sobre o mesmo.

De acordo com os dados obtidos na resolução e no site da SES-SP, esse profissional deve ter conhecimento técnico e habilidades comunicacionais. $\mathrm{O}$ conhecimento técnico se torna base para a atuação do articulador que, estando sempre em contato com os gestores municipais, busca propor ações e programas para qualificar a $\mathrm{AB}$. Conforme consta na resolução, este é um programa de apoio técnico que tem por finalidade assentir o desenvolvimento da capacidade da gestão municipal, mediante o "monitoramento e avaliação do desempenho e evolução da AB no estado"; e mediante "propostas de ações de intervenção e de capacitação em Atenção Básica, pactuadas junto aos Municípios, Colegiados de Gestão Regional e Departamentos Regionais de Saúde" (SÃO PAULO, 2011, s/p).

Em estudo anterior sobre a prática dos articuladores (DORICCI, 2014), apontamos o importante potencial transformador deste programa, no qual a atuação dos articuladores está fortemente pautada na comunicação, o que, inclusive, facilita a promoção de transformações, apesar dos desafios que o caracterizam. De modo geral, e com base na análise desenvolvida, é possível descrever parte da prática do articulador a partir de uma das atividades técnicas desempenhadas por eles: a visita aos municípios.

Esta atividade pode ser descrita, com base nas entrevistas realizadas com os articuladores, por três ações principais, que a compõem: realização de diagnóstico, instrução e negociação de propostas. Assim, os articuladores visitam os municípios com o intuito de promover o diagnóstico a partir da observação dos espaços físicos; observação da organização dos processos de trabalho; e principalmente através de conversas formais ou informais com os gestores e profissionais de saúde; ou da promoção de reuniōes, que se configuram como sendo a abertura de espaços para a discussão e reflexão das equipes. Após traçar um diagnóstico, o articulador pode instruir tecnicamente, ou negociar propostas 
de melhoria para qualificação da $\mathrm{AB}$, utilizando, também, para isso, as conversas formais ou informais e as reuniōes.

A partir da descrição desta atividade, identificamos que o articulador pode, com sua atuação, facilitar ações de humanização, embora não seja este o seu foco principal. Assim, consideramos que, apesar da especificidade do programa, suporte técnico criado no Estado de São Paulo para qualificar a $A B$, a análise da prática do articulador pode contribuir para a produção do conhecimento sobre assuntos amplamente discutidos, como a humanização no contexto da saúde.

\section{A Política Nacional de Humanização}

A Política Nacional de Humanização surge, também, no bojo das transformações decorrentes da Reforma Sanitária e da necessidade de reformulação das políticas e das práticas de saúde em prol dos preceitos conquistados, em 1988, com a instituição do SUS.

A humanização na saúde é tema discutido desde a década de 1950 (CASATE; CORRÊA, 2005). Deslandes (2006) descreve como marco desse debate, no campo da Sociologia Médica, o Seminário intitulado "Humanizing Health Care”, ocorrido em São Francisco, nos anos 1970. Assim, as discussões sobre a humanização no contexto de saúde, nacional e internacional (TRODES; GALVIN; HOLLOWAY, 2009; HOWARD; STRAUSS, 1975; DESLANDES, 2004), antecedem sua instituição como uma Política Pública do Brasil.

Atualmente, são inúmeras as produções científicas a respeito da humanização no contexto nacional (GUEDES; PITOMBO; BARROS, 2009; GUEDES; ROZA; BARROS, 2012; COTTA et al., 2013; MOREIRA et al., 2015). A Política Nacional define a humanização e delineia alguns aspectos-chave, mas a discussão destes se dá na literatura a partir de diferentes perspectivas teóricas, como Foucaultiana (NEVES; MASSARO, 2009; SOUZA; MENDES, 2009); Hermenêutica e Fenomenológica (SANTOS; SANTO, 2011; AYRES, 2005); Marxista (GOMES; SCHRAIBER, 2011) e Esquizoanalítica (ESCÓSSIA, 2009; CECCIM; MERHY, 2009). Levando em conta essa diversidade de análises, optamos por destacar as principais características desta política, conforme descritas em documentos publicados pelo Ministério da Saúde, e reforçar algumas discussões promovidas sobre o tema a partir de produções tidas como clássicas, uma vez que são amplamente referenciadas na literatura científica atual. 
A PNH é atualmente considerada uma política transversal, o que significa compreendê-la como um conjunto de princípios e diretrizes que se concretizam em ações nos diversos contextos e práticas de saúde, a partir de uma construção coletiva realizada no cotidiano (BENEVIDES; PASSOS, 2005; COTTA et al., 2013).

A humanização é definida pelo Ministério da Saúde como sendo "a valorização dos diferentes sujeitos implicados no processo de produção de saúde: usuários, trabalhadores e gestores" (BRASIL, 2008, p. 8), buscando promover a autonomia e o protagonismo dos mesmos; o aumento da corresponsabilidade; a participação coletiva na gestão; a possibilidade de mudança dos modelos de gestão e atenção, entre outros aspectos (BRASIL, 2008; GOMES; SCHRAIBER, 2011; CECCIM; MERHY, 2009; JUNGES et al., 2012; TRAD; ESPIRIDIÃO, 2010).

Portanto, a PNH estabelece princípios que valorizam o aspecto "humano" nas interações. Dessa maneira, as Ciências Humanas, e especificamente a Psicologia, têm contribuído com as discussōes levantadas neste campo. A política de humanização se configura como uma proposta de transformação que se inicia no âmbito micropolítico, nas interações. Ela não pretende estabelecer normas verticais a serem colocadas em prática, mas pretende fomentar uma nova cultura (JUNGES et al., 2012; SANTOS; SANTO, 2011), "um novo tipo de interação entre os sujeitos" (BRASIL, 2004; BENEVIDES; PASSOS, 2005), que destaque as singularidades, autonomia e responsabilidades dos indivíduos e de seus contextos, como os aspectos sociais que os envolvem.

A ideia central é a de promover uma cultura de valorização da qualidade do cuidado do ponto de vista técnico, de reconhecimento dos direitos do paciente, de suas subjetividades e aspectos culturais, e de valorização dos profissionais e da comunicação entre eles, intra e interequipes. Estes aspectos possibilitam a democratização das relações, a comunicação e diálogo entre profissionais e pacientes, sendo eles vistos como sujeitos ativos. Portanto, a prática de saúde, ao incorporar os aspectos da humanização, abre um novo campo de possibilidades para a melhoria da qualidade do atendimento e para a promoção de uma nova ordem relacional que considere o reconhecimento da alteridade no diálogo (DESLANDES, 2004; SANTOS; SANTO, 2011). ${ }^{1}$

Benevides e Passos (2005) apontam dois desafios principais para a concretização da humanização, os quais reputamos atuais: o desafio conceitual e o metodológico. 
O primeiro significa ultrapassar a visão da humanização como "conceito-sintoma" presente nas práticas de atenção pensadas a partir de uma fragmentação de áreas e níveis de atenção, relacionadas a algumas profissões específicas e orientadas por exigências de mercado que colocam a necessidade da qualidade dos serviços e enfoque nos clientes. Como "conceito-sintoma", a humanização é referida por sentidos estabilizados e instituídos, perdendo seu caráter de movimento instituinte. De acordo com os autores, há uma idealização do humano, sendo um desafio partir do que há de concreto. Nesse sentido, defendem uma visão de homem que o considere em sua diversidade e em sua constante transformação. Partem do conceito de sujeitos sociais, concretos e engajados em práticas locais, capazes de, em conjunto, transformar seu ambiente e a si próprios.

Com base nessa concepção de "humano", os autores supracitados consideram que a humanização depende de um investimento na produção de outras formas de interação, formas que fomentem o protagonismo e que destaquem o "SUS que dá certo”. Mas, como colocam, apenas redefinir o conceito não é suficiente. É preciso alterar as práticas concretas, por isso se impõe o outro desafio, o metodológico (BENEVIDES; PASSOS, 2005), que corresponde ao "como" fazer acontecer tal proposta de transformação conceitual na prática. Entende-se, nesse novo âmbito, que a prática deve superar a segmentação dos processos de trabalho, fortalecer os coletivos e promover mudanças nos processos de subjetivação, o que se concretiza nas "tecnologias relacionais".

De acordo com as informações destacadas até aqui, concluímos que o debate sobre a humanização no Brasil enfatiza, entre outros aspectos, as dimensões éticas do cuidado, das relações, bem como a importância da comunicação e do diálogo (DESLANDES; MITRE, 2009; AYRES, 2005; CECCIM; MERHY, 2009; SANTOS; SANTO, 2011; MOREIRA et al., 2015). Assim, considerando a importância do aspecto comunicacional (DESLANDES; MITRE, 2009; BENEVIDES; PASSOS, 2005; SANTOS; SANTO, 2011) como um recurso para a construção da humanização, além da importância dada ao protagonismo dos sujeitos e à corresponsabilidade dos mesmos, propomos a discussão produzida neste artigo a respeito da prática do articulador da atenção básica, uma vez que este desenvolve a atividade técnica "visita aos municípios" utilizando a comunicação como principal ferramenta de trabalho, além de estar em contato direto com os profissionais de saúde, gestores e usuários (DORICCI, 2014). 
Este artigo objetiva dar visibilidade às açōes concretas, conforme descritas pelos articuladores em entrevista, desenvolvidas por eles ao realizar esta atividade técnica, bem como às implicações dessas ações, segundo análise desenvolvida, que proporcionam e potencializam interaçôes que favoreçam a humanização em seu contexto de trabalho, a partir da ampliação da comunicação.

\section{Percurso metodológico}

Participaram da pesquisa todos os articuladores da atenção básica de uma das Redes Regionais de Atenção à Saúde do Estado de São Paulo (RRAS). Optamos por manter em sigilo o nome da Rede para resguardar a identificação dos profissionais. Esta rede inclui quatro Departamentos Regionais de Saúde (DRS) constituídos por doze Regiôes de Saúde. No total, foram entrevistados 13 articuladores, sendo 11 do sexo feminino e 2 do sexo masculino, com idade entre 37 e 60 anos, e formação profissional em Psicologia, Odontologia, Medicina e Enfermagem.

Foram realizadas entrevistas, com base em roteiro semiestruturado, que permitia abordar quatro temas principais: 1) Informaçôes gerais (dados demográficos); 2) Sobre a implantação do programa; 3) Descrição da prática atual e 4) Opinião sobre o programa.

Após aprovação do projeto em um Comitê de Ética em Pesquisa (CAAE 07576212.4.0000. 5407), entramos em contato com os articuladores para convidá-los a participar voluntariamente do estudo, os quais consentiram e assinaram o Termo de Consentimento Livre e Esclarecido.

As 13 entrevistas foram gravadas em áudio e transcritas na íntegra (PRETI, 1999). Foram omitidas, nas transcrições, algumas informações que pudessem facilitar a identificação dos participantes. A palavra "articulador" sempre aparece como um pronome masculino, independente do sexo do participante. As transcrições correspondem ao corpus da pesquisa.

A análise possui delineamento qualitativo com respaldo nas contribuições do movimento construcionista social em Psicologia (MCNAMEE, 2014), inspiração na abordagem teórico-metodológica das práticas discursivas e produção de sentidos (SPINK, 2004) e em um dos princípios norteadores da metodologia de pesquisa da Investigação Apreciativa (COOPERRIDER; WHITNEY, 2006), os quais guardam relação com a epistemologia construcionista social. 
O construcionismo social caracteriza-se por ser um movimento crítico em Psicologia paralelo às transformaçôes epistemológicas que ocorreram em disciplinas das Ciências Sociais e Humanas no último século (MCNAMEE, 2010), sendo um movimento multidisciplinar (BURR, 2003).

De modo geral e sintético, é possível identificar quatro aspectos principais reconhecidos como centrais às propostas construcionistas em ciência (GERGEN, 2009; BURR, 2003): 1) Posição crítica frente aos conhecimentos dados como universais e verdadeiros, reconhecendo que estes são construções teóricas; 2) Reconhecimento de que estas produções teóricas se transformam de acordo com o momento histórico e cultural; 3) Compreensão de que o conhecimento é sustentado por processos sociais; 4) Entendimento de que o conhecimento e as práticas sociais são indissociáveis, pois essas decorrem dos conhecimentos e os produzem. Assim, os modos de compreensão sustentam determinados padrões de ação e suprimem outros.

A pesquisa é reconhecida como uma prática discursiva fundamentada no processo de produção de sentido (SPINK, 2004). Sendo assim, mais do que a produção de um conhecimento neutro, verdadeiro e universal a respeito da realidade, é compreendida como uma prática social e discursiva sustentada pelos pesquisadores e participantes que conjuntamente constroem os resultados propostos a partir dos sentidos produzidos e categorizados ao longo do percurso da investigação. O pesquisador não é considerado uma figura neutra, pois sua participação em determinados contextos históricos, culturais e sociais delimita as possibilidades de construção de sentido, de categorização, que caracterizam os resultados de sua análise. Da mesma forma, o fato de não participar ativamente do contexto pesquisado delimita as possibilidades de significação do pesquisador, podendo este trazer diferentes olhares para o contexto estudado, e, partindo de uma epistemologia construcionista social, construir outros significados sobre as práticas pesquisadas.

A abordagem metodológica da Investigação Apreciativa (IA) surge no contexto organizacional. A ideia fundamental desta metodologia é envolver todos os participantes do contexto investigado em busca de uma construção de sentido que seja coletiva e compartilhada e a favor de mudanças que sejam necessárias. O foco desta ferramenta recai sobre a construção conjunta de realidades sociais a partir 
1280 de experiências passadas, e que tenham sido positivas, com o objetivo de levar os participantes do contexto a pensarem sobre o futuro (NILSON et al., 2014).

A IA tem sido apontada como importante ferramenta metodológica para a realização de pesquisas em saúde coletiva. A justificativa para esta utilização se consolida no princípio da integralidade e na necessária integração dos saberes através da atuação das equipes multiprofissionais (NILSON et al., 2014). Embora a pesquisa descrita no presente artigo não tenha sido realizada nos moldes da IA, utilizamos como inspiração para a análise do corpus um dos princípios que norteiam a relação do pesquisador com o contexto pesquisado, o princípio "positivo".

Entre os princípios que guiam a atuação do pesquisador na IA, o princípio "positivo" dá enfoque às potencialidades, aos aspectos positivos do contexto já colocados em prática (NILSON et al., 2014). A partir deste princípio, ao entrar em relação com o corpus da pesquisa, buscamos destacar dos relatos os aspectos positivos descritos pelos articuladores sobre sua atuação, os quais notamos proporcionar uma ampliação da comunicação no contexto de trabalho e, consequentemente, uma possibilidade para a construção de interações mais corresponsáveis e protagonistas.

Após a leitura em profundidade das transcriçôes, percebemos que a "visita aos municípios” propicia uma atuação centrada na comunicação. Nesse sentido, procuramos recortar das entrevistas os sentidos construídos sobre esta atividade e suas implicações, que poderiam ser descritos e analisados de acordo com o referencial teórico da $\mathrm{PNH}$ e seu enfoque na comunicação e nas interações cotidianas. Importante ressaltar que este recorte analítico fundamenta-se nas entrevistas realizadas. Sendo assim, partimos dos sentidos construídos na interação dos articuladores com a pesquisadora sobre sua prática profissional, porém, esta metodologia de análise não alcança uma descrição detalha de "como" os articuladores atuam, como interagem e se comunicam, e quais resultados esta prática proporciona. A análise aqui descrita pretende abordar e destacar uma descrição da função do articulador que potencialize sua atuação considerando, também, que o enfoque na comunicação, a depender do modo como ocorre, permite a construção da humanização no cotidiano.

Em resumo, descrevemos os seguintes passos de análise realizados neste estudo: $1^{\circ}$ ) Transcrição literal do material, em que buscamos manter as falas 
no modo como ocorreram, incluindo o uso de siglas e de linguagem coloquial.

Esta etapa é considerada parte da produção de sentidos, pois pontuar as falas e fazer comentários sobre o "como" ocorreram as conversas constitui-se como parte desse processo (GUANAES; JAPUR, 2008); 2º Leitura em profundidade do material, para que aos poucos fosse possível reconhecer, no fluxo conversacional, os principais sentidos descritos sobre a "visita aos municípios"; 3) Descrição e análise desta atividade e de suas implicações, a partir dos sentidos construídos sobre ela nas entrevistas e do referencial teórico da humanização em saúde .

Aseguir, apresentamos os resultados conforme análise proposta, juntamentecom alguns trechos das entrevistas realizadas. Os trechos apenas ilustram a construção temática desenvolvida na análise, são recortes de um fluxo conversacional que em seu conjunto nos possibilitou desenhar os resultados aqui descritos.

\section{Resultados e Discussão}

A análise dos sentidos construídos sobre as ações da atividade técnica "visita aos municípios" reforça a informação encontrada de que a atuação dos articuladores ocorre, em grande medida, com base no conhecimento técnico que possuem e nas habilidades comunicacionais necessárias (ANDRADE; CASTANHEIRA, 2011; SÃO PAULO, 2011)

Assim, a comunicação, segundo a análise descrita, corresponde a uma das principais ferramentas de trabalho desses profissionais. É através da comunicação que os articuladores concretizam as ações que compõem a "visita aos municípios", quais sejam: realização de diagnóstico, fornecimento de instruções e negociação de propostas. Portanto, a depender do modo como atuam, como se comunicam em seu contexto de trabalho, podem gerar implicaçôes, observadas nos relatos das entrevistas, que potencialmente contribuem para a promoção da humanização.

A partir da análise, construímos três temas que correspondem às três implicações, ou consequências, da atividade "visita aos municípios", que possibilitam a abertura de espaços de comunicação: ampliação da comunicação intra e intergrupos; escuta das necessidades locais; e promoção de espaços para discussão.

\section{Ampliação da comunicação intra e intergrupos}

Ao realizar as visitas, os articuladores promovem um contato direto com a SESSP, com o DRS e com os gestores e profissionais que atuam na ponta do sistema 
1282 de saúde. Uma das implicações possíveis desta atuação é a ampliação do contato e diálogo entre os diferentes profissionais e instituições.

Ao visitar o município, o articulador dialoga, questiona os profissionais sobre seu cotidiano, levando-os a refletir sobre seu contexto de trabalho. Estes, muitas vezes, se reúnem para discutir junto com o articulador alguns aspectos. Além de conversar diretamente com os profissionais, os articuladores podem ainda se reunir com o secretário de saúde dos municípios e com o coordenador da Atenção Básica do Estado de São Paulo. De certa forma, o articulador, com seu papel, acaba promovendo uma ampliação da comunicação intragrupo (dentro das próprias Unidades de Saúde) e também intergrupos (entre Unidades de Saúde e equipes de outros setores dentro do próprio DRS, como Vigilância Epidemiológica, Centro de Desenvolvimento e Qualificação, e dentro da Secretaria Estadual de Saúde quando necessário). Embora seja possível identificar, a partir dos relatos dos participantes das entrevistas, essa possibilidade de ampliação da comunicação, não é possível analisar o modo como essa comunicação ocorre na prática, uma vez que não acompanhamos os articuladores em sua atividade. Apesar disso, consideramos que o fato de haver uma função profissional com este papel previsto já se configura como algo bastante inovador, abrindo possibilidades importantes para o contexto em análise. Como muitos participantes descrevem, eles são o "elo" das diferentes instâncias, conforme ilustra o trecho a seguir:

E10: [...] então eu acho que a gente consegue tanto ser esse elo de ligação entre gestão e município como também ser um elo de ligação entre a regional, be/ intra-regional mesmo, e da regional com eles... né?

Esse contato ampliado pode favorecer não só a horizontalidade das interações, como, em muitas situações, a transversalidade da comunicação, o que possibilita açōes entre setores e a qualificação da AB. Ao buscarem aprimorar a $\mathrm{AB}$ do município, os articuladores acabam envolvendo as diversas equipes dos setores que fazem parte da rede de atenção à saúde, não apenas dos municípios, mas da própria região. Muitas vezes, os articuladores auxiliam nas reuniōes do Colegiado de Gestão Regional onde se discutem ações intermunicipais.

Como descrito na introdução, a PNH busca promover a transversalidade da comunicação, sendo este um princípio norteador da política que objetiva fomentar a comunicação intra e intergrupos em prol da construção de potencialidades que 
favoreçam interaçōes condizentes com os princípios da PNH (BRASIL, 2008;

BRASIL, 2010; BENEVIDES; PASSOS, 2005). Sendo assim, o articulador, com sua atuação, pode facilitar essa ampliação comunicacional que se pretende com a $\mathrm{PNH}$, e, consequentemente, fomentar melhoria na qualidade da prestação de serviços de saúde, objetivo primordial da Política de Humanização e razão pela qual a política foi criada (MOREIRA et al., 2015). No entanto, destacamos que o aumento da comunicação intra e intergrupos é apenas um primeiro passo, uma vez que o modo como essa comunicação ocorre na prática é o que fundamenta os resultados obtidos.

\section{Escuta das necessidades locais}

Ao ouvir as necessidades e dificuldades dos profissionais, estando em contato com a realidade local, o articulador pode criar vínculo com eles, passando a perceber quais são as possibilidades de melhoria na qualidade da prestação de serviços de saúde à população. $\mathrm{O}$ contato direto, muitas vezes, faz com que o articulador possa ser reconhecido como alguém que participa do cotidiano de trabalho dos profissionais, o que pode facilitar as ações de instrução técnica e, até mesmo, as de negociação. Ao se sentirem ouvidos, e ao terem espaços para discutir e refletir, os profissionais de saúde tendem a se tornar protagonistas das propostas, passando, frequentemente, a se corresponsabilizar por elas. Destacamos que a escuta em si não garante estes resultados, mas sim o modo como esta interação vai sendo construída, algo que escapa ao objetivo deste artigo, que pretende dar destaque para esta potência existente na função do articulador.

E10: ... e as equipes assim gostam de sentar pra conversar... [...] também é muito interessante a troca de experiência entre as... isso não acontecia [...] e isso não existia, esse diálogo entre todos...

Pesquisadora: é algo que o articulador conseguiu contribuir...

E10: conseguimos conse/ ... [...] é muito legal essa troca entre as equipes... muito legal, antes eu sentia que eu era muito mais protagonista, hoje não... hoje eu sinto que eu to mais assim... sabe na?... eu não sou tão protagonista nesse processo, né?

Pesquisadora: que hum/ o que te fez mudar?

E10: eu acho que o pro/ o pr/ o próprio crescimento da equipe...

Pesquisadora: ah tá... 
E10: né? o próprio crescimento da equipe, você vê que a equipe, ela começa a ter pernas próprias, isso que é, isso que é interessante, e eu acho que é esse nosso papel... você fortalecer mesmo pra que ela ande sozinha, né? não precisa... não precisa ter a figura do articulador pra que aquela reunião aconteça [...].

E13: [...] esse é o papel do articulador, não é? É melhorar e capacitar a equipe e tem que... trabalhar junto com a gestão, então eu tenho conseguido conversar com a equipe e conversar com a gestão...

Com essa abordagem, o articulador pode promover aprimoramentos nas condições de trabalho, através de suas propostas, ou das reflexões que dispara com suas questões. Em muitos casos, acaba favorecendo a melhoria das interações entre os profissionais, que passam a se sentir ouvidos em suas necessidades e a perceber a abertura ao diálogo como fundamental. Obviamente, a inserção do articulador pode também iniciar processos de reflexão que acarretam conflitos ou processos de mudança não desejados. Porém, buscamos neste artigo destacar o potencial positivo dessas implicações, entendendo-o como campo promissor para pensarmos práticas que sejam mais humanizadas, de forma que os profissionais e pacientes sintam-se fundamentais para a construção da saúde. Esta participação ativa, certamente, inclui impasses e negociação de diferenças, uma vez que todos são considerados protagonistas. Como colocado na introdução, a busca por aperfeiçoamento das condições de trabalho (BRASIL, 2008); a valorização do trabalho e do trabalhador enquanto protagonistas (BRASIL, 2010) e a ampliação do diálogo (DESLANDES, 2004) são aspectos valorizados pela PHN.

De certa forma, esta atuação do articulador ilustra uma possibilidade para se trabalhar o desafio metodológico abordado por Benevides e Passos (2005), com a ressalva de que este desafio, dificilmente, supera-se por completo. Estar em contato direto com os profissionais e municípios, como colocado no item anterior, fomenta o aumento da comunicação entre os diversos setores responsáveis pela promoção da saúde e, ao mesmo tempo, possibilita que surjam práticas locais de valorização do trabalho e das ações possíveis para cada contexto.

\section{Promoção de espaços para discussão}

Outro aspecto valorizado pela política, a formação de sujeitos corresponsáveis, torna-se possível mediante a atuação do articulador ao promover espaços para a discussão, ou reforçar a importância das reuniōes. Essa prática tem 
potencialidade para desenvolver o protagonismo dos profissionais de saúde e das equipes, e facilitar a interação entre eles para que consigam se articular e se corresponsabilizar pela qualidade das ações e serviços oferecidos à população. Estes espaços para discussão também se constituem como importante aspecto da PNH. Como descrito pelo Ministério da Saúde (BRASIL, 2009, p. 15), "É nestes encontros, onde as pessoas conversam, que os problemas podem e devem aparecer, ser analisados e enfrentados. É nestes espaços que se pode construir corresponsabilidade e aumentar o grau de autonomia de cada um".

E10: então sempre a gente discute juntos, né?... e a pauta, sempre é trazida pelas equipes de atenção básica...

Pesquisadora: é de acordo com a necessidade deles...

E10: [...] você sabe pra onde ir... você poderia chegar no final... mas, se a equipe não chega ela não se responsabiliza...

E8: eu vejo umas equipes muito frágeis, né? então a gente tenta... né? eu vou falar mais específico de mim, eu tento fazer com que elas se empoderem mais, né?

Uma das orientações estratégicas para a implementação da $\mathrm{PNH}$ relacionada ao eixo de gestão do trabalho propõe açôes que facilitem a presença dos trabalhadores em processos de discussão e decisão, para que participem ativamente da gestão (BRASIL, 2004). A atuação do articulador, ao fomentar discussões tanto com os trabalhadores quanto com os gestores, promove, mesmo que minimamente, a possibilidade de participação dos trabalhadores no processo de gestão. Ao fazer a negociação entre as necessidades dos profissionais, as necessidades políticas da gestão e as necessidades de saúde do município, o articulador favorece o protagonismo dos profissionais, podendo implicá-los em seus processos de trabalho e nos resultados que eles obtêm.

Ao dialogar com a equipe, o articulador pode fomentar reflexão, o que faz com que os profissionais de saúde se sintam capazes de solucionar algumas dificuldades que enfrentam em seu cotidiano de trabalho. Ainda que haja problemas estruturais que fogem ao controle das equipes, em alguns casos, é possível que eles consigam coordenar suas ações para promover mudanças. Embora seja possível apontar este recurso, a partir do relato dos articuladores, a análise proposta não alcança o modo como os articuladores têm realizado esse momento, uma vez que sua atuação não foi observada na prática. 


\section{Considerações finais}

Com base na análise proposta, é possível concluir que, embora o articulador da atenção básica não tenha como foco de atuação a promoção da humanização, ao estabelecer contato direto com os diversos atores no campo da saúde, e ao utilizar uma abordagem fortemente pautada na comunicação e na abertura de espaços de conversa, ele pode contribuir para a qualificação da atenção básica, e para a promoção da humanização das práticas, sejam elas de assistência ou gestão. Fazse necessário ressaltar que esta abertura de espaços de conversa corresponde a um primeiro passo importante para a construção de interaçóes que se aproximem do que preconiza a PNH. Contudo, o fator central que possibilita ou não uma transformação dos contextos em que o articulador atua corresponde ao modo como essas interações se estabelecem, algo que a metodologia do presente estudo não alcança em sua análise. Nesse sentido, destacamos a necessidade de novos estudos que possam alcançar esta dimensão do "como" estão sendo colocados em prática esses espaços relatados pelos articuladores como fortemente pautados na comunicação, e que são aqui descritos como potentes para transformaçôes fundamentadas nos princípios da humanização.

Assim, embora destaquemos o potencial humanizador da função do articulador, não há garantias de que as implicações humanizadoras descritas neste artigo ocorram sempre. As entrevistas foram realizadas em apenas uma das RRAS do estado, portanto, não sabemos como tem sido construída a atuação dos articuladores nas demais redes. Além disso, dentro da própria RRAS analisada, percebemos diferenças individuais e contextuais que podem facilitar ou cercear a atuação pautada no diálogo e na reflexão. Não são todos os articuladores que descrevem uma prática pautada na abertura de espaços para conversa, da mesma forma que não são todos os municípios que mantêm este contato com o articulador de forma produtiva. Alguns demonstram uma atuação mais individual e técnica.

Ao descrever a função desses profissionais como potencial transformador a favor do processo de humanização, buscamos ressaltar as potencialidades da atuação fortemente pautada no diálogo, observadas em algumas entrevistas, e, ao mesmo tempo, abrir novas possibilidades práticas e discursivas a respeito deste programa, que atualmente se destaca pelo suporte técnico oferecido. 
A proposta desta análise é exaltar o trabalho de humanização que se torna possível ao construírem espaços dialógicos em seus encontros com os profissionais de saúde e ao ampliarem a escuta sobre suas necessidades e dificuldades. Não buscamos com isto transparecer uma visão ingênua, como se não houvesse desafios para a operacionalização das atividades dos articuladores. Dentre os desafios apontados por eles próprios estão a falta de recursos, de abertura de alguns municípios, sobrecarga de trabalho, dúvidas quanto ao como deveriam agir, enfrentamento de interesses políticos que dificultam sua atuação, entre outros (DORICCI, 2014).

Entendemos que esta visão pautada na capacidade pode motivar os articuladores a se sentirem protagonistas de mudanças que sejam necessárias, a partir das qualidades que já possuem e desenvolvem em seu contexto de trabalho. Assim, concluímos que o articulador da atenção básica, criado por um programa estadual, possui potencial para facilitar o diálogo entre os diversos atores com os quais tem contato, além de qualificar a $\mathrm{AB}$, o que, consequentemente, pode contribuir para que o processo de humanização se inicie nas interações estabelecidas no ambiente de trabalho. Porém, para que esse potencial se atualize no cotidiano é preciso uma análise constante da prática desses profissionais, sobre o modo como se posicionam e posicionam os demais ao abrirem espaços de conversa, e investimento nesse sentido daqueles que acompanham este programa. ${ }^{2}$

\section{Referências}

ANDRADE, M. C.; CASTANHEIRA, E. R. L. Cooperação e Apoio Técnico entre Estado e Municípios: a experiência do Programa Articuladores da Atenção Básica em São Paulo. Saúde e Sociedade, v. 20, n. 4, p. 980-990, 2011.

AYRES, J. R. C. M. Hermenêutica e humanização das práticas de saúde. Ciência \& Saúde Coletiva, v. 10, n. 3, p. 549-560, 2005.

BENEVIDES, R.; PASSOS, E. Humanização na saúde: um novo modismo? Interface. Botucatu, v. 9, n. 17, p. 389-406, mar.-ago., 2005.

BRASIL. Ministério da Saúde. Secretaria de Atenção à Saúde. Departamento de Ações Programáticas Estratégicas. Política Nacional de Humanização da Atenção e Gestão do SUS. Programa de formação em saúde do trabalhador. Série B. Textos Básicos de Saúde. Brasília: Ministério da Saúde; 2010. 
Ministério da Saúde. Secretaria de Atenção à Saúde. Política Nacional de Humanização da Atenção e Gestão do SUS. O HumanizaSUS na atenção básica. Série B. Textos Básicos de Saúde. Brasília: Ministério da Saúde; 2009.

Ministério da Saúde. Secretaria de Atenção à Saúde, Núcleo Técnico da Política Nacional de Humanização. Humaniza SUS. Documento Base para Gestores e Trabalhadores do SUS. 4. ed. Série B. Textos Básicos de Saúde. Brasília: Ministério da Saúde; 2008.

- Ministério da Saúde. Secretaria-Executiva. Núcleo Técnico da Política Nacional de Humanização. HumanizaSUS: Política Nacional de Humanização. A Humanização como Eixo Norteador das Práticas de Atenção e Gestão em Todas as Instâncias do SUS. Série B. Textos Básicos de Saúde. Brasília: Ministério da Saúde; 2004.

BURR, V. Social Construcionism. 2. ed. New York: Routledge, 2003.

CADONÁ, E.; SCARPARO, H. Construcionismo Social na Atenção Básica: uma revisão integrativa. Ciência \& Saúde Coletiva, v. 20, n. 9, p. 2721-2730, 2015.

CAMARGO-BORGES, C. O Construcionismo Social no contexto da Estratégia de Saúde da Família: articulando saberes e práticas. 2007, 207 p. Tese (Doutorado) - Escola de Enfermagem de Ribeirão Preto, Universidade de São Paulo, São Paulo.

CASATE, J. C.; CORRÊA, A. K. Humanização do atendimento em saúde: conhecimento veiculado na literatura brasileira de enfermagem. Revista Latino-Americana de Enfermagem, v. 13, n. 1, p. 105-111, jan.-fev., 2005.

CECCIM, R. B.; MERHY, E. E. Um agir micropolítico e pedagógico intenso: a humanização entre laços e perspectivas. Interface. Botucatu, v. 13, supl. 1, p. 531-542, 2009.

COOPERRIDER, D. L.; WHITNEY, D. Investigação apreciativa: uma abordagem positiva para a gestão de mudanças. Qualitymark, 2006.

COTTA, R. M. M. et al. Debates atuais em humanização: quem somos nós? Ciência \& Saúde Coletiva, v. 18, n. 1, p. 171-179, 2013.

DESLANDES, S. F. Análise do discurso oficial sobre a humanização da assistência hospitalar. Ciência \& Saúde Coletiva, v. 9, n. 1, p. 7-14, 2004.

Humanização: revisitando o conceito a partir das contribuições da sociologia médica. In. DESLANDES, S. F. (Org.). Humanização dos cuidados em saúde: conceitos, dilemas e práticas. Rio de Janeiro: Editora Fiocruz, 2006. (Coleção Criança Mulher e Saúde).

DESLANDES, S. F.; MITRE, R. M. A. Processo comunicativo e humanização em saúde. Interface. Botucatu, v. 13, n. 1, p. 641-649, 2009.

DORICCI, G.C. A prática dos articuladores da atenção básica: comunicação e mudança do modelo de atenção em saúde. 2014, 155 p. Dissertação (Mestrado) - Faculdade de Filosofia Ciências e Letras de Ribeirão Preto, Universidade de São Paulo, São Paulo. 
ESCÓSSIA, L. O Coletivo como plano de criação na Saúde Pública. Interface. Botucatu, v. 13, supl. 1, p. 689-694, 2009.

FRANCO, T. B.; MERHY, E. E. Programa de Saúde da Família (PSF): Contradições de um Programa destinado à mudança do modelo tecnoassistencial. In: MERHY, E. E. et al. O trabalho em saúde: olhando e experienciando o SUS no cotidiano. São Paulo: Hucitec, 2006, p. 55-133.

GERGEN, K. O movimento do construcionismo social na Psicologia moderna. Trad. E. J. S. Filho. Interthesis, v. 6, n. 1, p. 299-325, jan.-jul., 2009.

GOMES, R. M.; SCHRAIBER, L. B. A dialética da humanização-alienação como recurso à compreensão crítica da desumanização das práticas de saúde: alguns elementos conceituais. Interface. Botucatu, v. 15, n. 37, p. 339-50, abr.-jun., 2011.

GUANAES, C.; JAPUR, M. Contribuições da poética social à pesquisa em psicoterapia de grupo. Estud. psicol. Natal, v. 13, n. 2, p. 117-124, maio-ago., 2008.

GUEDES, C. R.; PITOMBO, L. B.; BARROS, M. E. B. Os processos de formação na Política Nacional de Humanização: a experiência de um curso para gestores e trabalhadores da atenção básica em saúde. Physis:Revista de Saúde Coletiva. Rio de Janeiro, v. 19, n. 4, p. 1087-1109, 2009.

GUEDES, C. R.; ROZA, M. M. R.; BARROS, M. E. B. O apoio institucional na Política Nacional de Humanização: uma experiência de transformação das práticas de produção de saúde na atenção básica. Cadernos de Saúde Coletiva. UFRJ, v. 20, p. 93-101, 2012.

HOWARD, J.; STRAUSS, A. Humanizing Health Care. Health, Medicine and Society: A Wiley-Interscience Series. New York: Wiley, 1975.

IBÁÑEZ GRACIA, T. La dimensión política de la psicologia social. Revista Lationoamericana de Psicologia, v. 25, n. 1, p. 19-34, 1993.

JUNGES, J. R. et al. O discurso dos profissionais sobre a demanda e a humanização. Saúde e Socidade, v. 21, n. 3, p. 686-697, 2012.

McNAMEE, S. Construindo conhecimento / construindo investigação: coordenando mundos de pesquisa. In. GUANAES-LORENZI, C. et al. (Orgs.). Construcionismo Social: discurso, prática e produção do conhecimento. Rio de Janeiro: Instituto Noos, 2014.

. Research as social construction: transformative inquiry. Saúde \& Transformação Social (on-line), v. 1, n. 1, p. 9-19, 2010.

MENDES, E. V. Os grandes dilemas do SUS. Tomo II. Salvador: Casa da Qualidade, 2001. MOREIRA, M. A. D. M. et al. Políticas públicas de humanização: revisão integrativa da literatura. Ciência \& Saúde Coletiva, v. 20, n. 10, p. 3231-3242, 2015.

NEVES, C. A. B.; MASSARO, A. Biopolítica produção de saúde e um outro humanismo. Comunic., Saúde, Educ, v. 13, supl. 1, p. 503-14, 2009. 
NILSON et al. A Investigação apreciativa como tecnologia para a pesquisa em Saúde Coletiva. Saúde \& Transformação Social, v. 5, n. 3, p. 01-09, 2014.

PINHEIRO, R. L.; GUANAES-LORENZI, C. Funções do agente comunitário de saúde no trabalho com redes sociais. Estudos de Psicologia. UFRN, v. 19, p. 48-57, 2014.

PRETI, D. Análise de textos orais. 4. ed. São Paulo: Humanitas Publicações FFCLRP/USP, 1999 (Série projetos paralelos v. 1).

SANTOS, J. G. W.; SANTO, M. A. A. E. Administração de Recursos Humanos em Saúde e Humanização: o viés hermenêutico. Rev Pan-Amaz Saúde, v. 2, n. 3, p. 51-58, 2011.

SÃO PAULO (Estado). Resolução SS n. 61, de 14 de Junho de 2011. Dispõe sobre o Programa de Apoio Técnico à Atenção Básica em Saúde (ABS) do Sistema Único de Saúde SUS no estado de São Paulo, monitoramento e avaliação da Atenção Básica e dá providências correlatas. Diário Oficial [Poder Executivo] do Estado de São Paulo, n. 112 DOE de 15 jun. 2011, seção 1, p. 115.

SECRETARIA ESTADUAL DA SAÚDE. Governo do Estado de São Paulo. Site: <http:// www.saude.sp.gov.br/ses/perfil/gestor/atencao-basica/Programa-articuladores-de-atencaobasica/articuladores-da-atencao-basica>. Acesso em: 05 jan. 2012.

SILVA, G. M.; RASERA, E. F. A construção do SUS-problema no jornal Folha de S. Paulo. História, Ciências, Saúde - Manguinhos. Rio de Janeiro, v. 21, p. 61-76, 2014.

SOUZA, L. A. P.; MENDES, V. L. F. O conceito de humanização na Política Nacional de Humanização (PNH). Interface. Botucatu, v. 13, supl 1, p. 681-8, 2009.

SPINK, M. J. P. (Org.). Práticas discursivas e produção de sentidos no cotidiano: aproximaçōes teóricas e metodológica. 3. ed. São Paulo: Cortez, 2004.

TIVERON, J. P.; GUANAES-LORENZI, C. Tensões do trabalho com grupos na Estratégia Saúde da Família. Psico (on-line). PUCRS, v. 44, p. 391-401, 2013.

TRAD, L. A. B.; ESPIRIDIĀO, M. A. Sentidos e práticas da humanização na Estratégia de Saúde da Família: a visão de usuários de seis municípios do Nordeste. Physis Revista de Saúde Coletiva. Rio de Janeiro, v. 20, n. 4, p. 1099-1117, 2010.

TRODES, L.; GALVIN, K. T.; HOLLOWAY, I. The humanization of healthcare: A value framework for qualitative research. International Journal of Qualitative Studies on Health and Well-being, v. 4, 2009, p. 68-77.

\section{Agradecimentos}

Agradecemos à Agência de Fomento Fundação de Amparo à Pesquisa do Estado de São Paulo (FAPESP). 
${ }^{1}$ Importante destacar que os termos interação e relação são utilizados, muitas vezes, como sinônimos nas produções específicas sobre humanização. No entanto, considerando as diferenças epistemológicas que dão origem a cada um dos termos em Psicologia Social, adotamos a palavra "interação" para nos referir aos momentos de encontro, e mantivemos "relação" conforme utilizada pelos autores referenciados.

${ }^{2}$ G. C. Doricci responsabilizou-se por todas as etapas da pesquisa, desde a realização das entrevistas, transcrições, até a redação do artigo. C. G. Lorenzi orientou todas as etapas da pesquisa e participou da elaboração do artigo. M. J. B. Pereira contribuiu para a discussão realizada e revisão teórica do material. 


\section{Abstract}

Articulators of Primary Care Program:
building humanization through dialogue The National Humanization Policy (NHP) advocates improving the delivery of health services through the valorization of the individuals involved in this process and their forms of interaction. Psychology has been an important reference for reflections and analyzes on humanization in the field of Public Health. This article aims to analyze one of the technical activities of the articulators of Primary Care, professionals of a new program of São Paulo, based on the precepts established by the NHP and its interface with the studies of Social Psychology. For this, 13 Primary Care articulators were individually interviewed. The analysis is qualitative, with theoretical support in the contributions of the social constructionist movement. As results, three implications of the articulators' actions are presented and that allow the promotion of humanization: expansion of intra and intergroup communication; listening to local needs and promoting spaces for discussion.

> Keywords: primary health care; health management; humanization of care; communication. 